\title{
Towards chiral diamines as chiral catalytic precursors for the borane-mediated enantioselective reduction of prochiral ketones
}

\author{
DEEVI BASAVAIAH*, UTPAL DAS and SUPARNA ROY \\ School of Chemistry, University of Hyderabad, Hyderabad 500046 \\ e-mail: dbsc@uohyd.ernet.in
}

MS received 28 April 2009; accepted 26 June 2009

\begin{abstract}
Two chiral diamines (3S)-3-anilinomethyl-1,2,3,4-tetrahydroisoquinoline (1) and (2R)-2anilinomethylpiperidine (2) have been employed as chiral catalytic sources in the borane-mediated asymmetric reduction of prochiral ketones thus providing the resulting secondary alcohols in good enantiomeric purities (up to $81 \%$ ee).
\end{abstract}

Keywords. (3S)-3-Anilinomethyl-1,2,3,4-tetrahydroisoquinoline; (2R)-2-anilinomethylpiperidine; $(S)$ phenylalanine; asymmetric reduction.

\section{Introduction}

Development of an efficient chiral catalyst for the borane-mediated asymmetric reduction of prochiral ketones providing the resulting secondary alcohols in high enantioselectivities has been and continues to be one of the most fundamental reactions and attractive endeavours in the chemistry of chiral reductions because of the challenges involved in such endeavours. ${ }^{1-12}$ We have been working in this direction for the past few years and developed some novel chiral catalysts mainly built on the (2S)-2anilinomethylpyrrolidine framework (3) for boranemediated asymmetric reduction processes. ${ }^{13-21}$ In continuation of our efforts in designing and developing useful chiral catalysts for the borane-mediated asymmetric reduction of prochiral ketones we report here the application of two chiral diamines (3S)-3anilinomethyl-1,2,3,4-tetrahydroisoquinoline (1) and (2R)-2-anilinomethylpiperidine (2) as chiral precursors (catalytic sources) for reduction of prochiral ketones to provide the resulting secondary alcohols in reasonably good enantioselectivities.

\section{Experimental}

All melting points were recorded on a Superfit (India) capillary melting point apparatus and were

*For correspondence uncorrected. IR spectra were recorded on Jasco-FTIR model 5300. ${ }^{1} \mathrm{H}$ NMR (400 MHz) and ${ }^{13} \mathrm{C}$ NMR $(100 \mathrm{MHz})$ spectra were recorded in deuterochloroform $\left(\mathrm{CDCl}_{3}\right)$ on a Bruker-Avance 400 spectrometer using tetramethylsilane (TMS, $\delta=0$ ) as an internal standard. Elemental analyses were recorded on a thermo Finnigan Flash 1112 analyzer. Mass spectra were recorded on Shimadzu LCMS 2010A mass spectrometer. The X-ray diffraction measurements were carried out at $298 \mathrm{~K}$ on a Bruker SMART APEX CCD area detector system equipped with a graphite monochromator and a Mo-K $\alpha$ fine-focus sealed tube $(\lambda=0.71073 \AA)$. HPLC analyses of alcohols were carried out on Shimadzu LC-10AD instrument using chiral column (Chiralcel OD-H or Chiralcel OJ-H). Optical rotations were measured on Jasco DIP 370 digital polarimeter. We have provided all the experimental details using the catalyst, (3S)-3-anilinomethyl-1,2,3,4-tetrahydroisoquinoline (1) as a representative case since all the other relevant data using the catalyst, $(2 R)$-2-anilinocarbonylpiperidine (2). We have earlier prepared $[(S)-10 a-c$ and $(R)-10 \mathrm{~d}, \mathrm{e}]$ molecules and reported the spectral data. ${ }^{18,21}$ The present spectral data (IR, ${ }^{1} \mathrm{H}$ NMR, ${ }^{13} \mathrm{C}$ NMR) are in agreement with the earlier data.

\section{1 (3S)-2-(tert-Butoxycarbonyl)-3-}

anilinocarbonyl-1,2,3,4-tetrahydroisoquinoline (7)

This compound was prepared following the literature procedure ${ }^{7}$ from compound (3S)-N-(tert- 


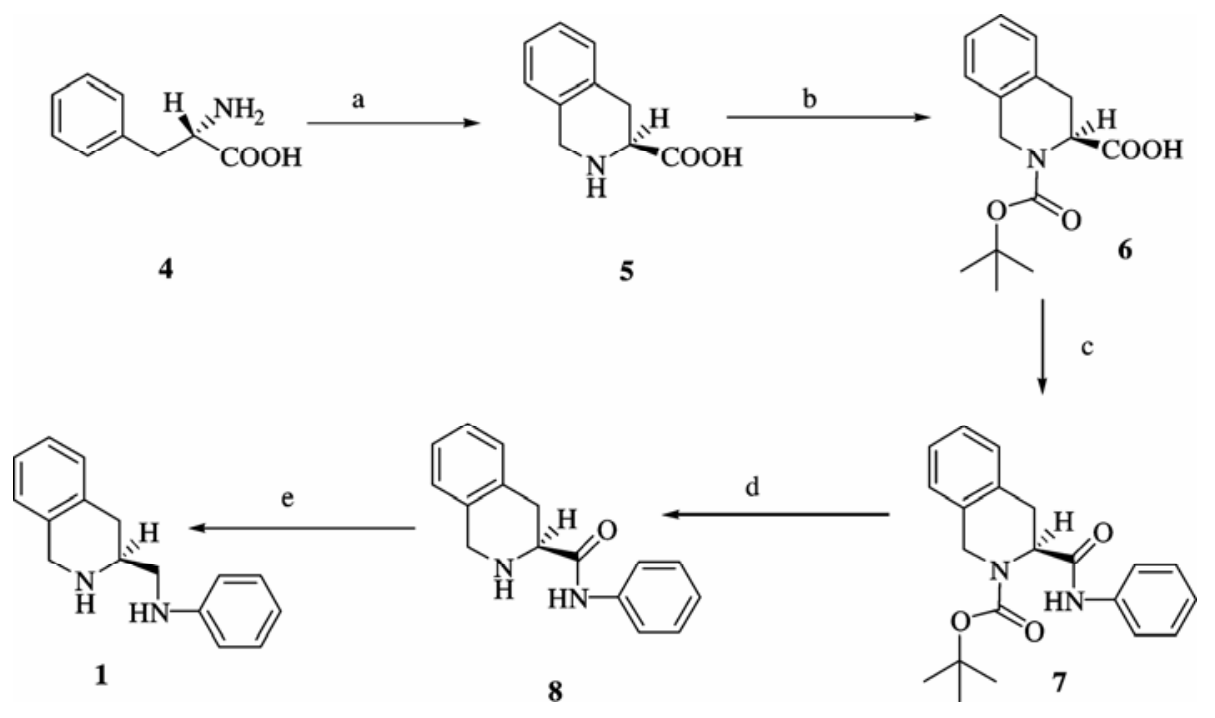

Scheme 1. (a) $37 \%$ aq. $\mathrm{HCHO}, \mathrm{HCl}, 60^{\circ} \mathrm{C}, 4 \mathrm{~h}, 30 \%,{ }^{23}$ (b) (Boc) $)_{2} \mathrm{O}$, aq. $\mathrm{NaOH}$, dioxane, r.t., 16 h, 74\%, ${ }^{22}$ (c) $\mathrm{NEt}_{3}$, EtOCOCl, $\mathrm{PhNH}_{2}, \mathrm{THF}, \mathrm{rt}, 16$ h, 66\%, ${ }^{7}$ (d) $\mathrm{HCl}(\mathrm{g}), \mathrm{CH}_{2} \mathrm{Cl}_{2}$, r.t., $30 \mathrm{~min}, 93 \%$; (e) $\mathrm{LiAlH}_{4}$, THF, reflux, 5 h, $84 \%$.

butoxycarbonyl)-1,2,3,4-tetrahydro-3-isoquinolinecarboxylic acid (6) which was obtained ${ }^{22}$ from (3S)1,2,3,4-tetrahydro-3-isoquinolinecarboxylic acid (5). Compound 5 was in turn prepared from (S)phenylalanine (4) following the known procedure as presented in the scheme $1 .{ }^{23}$

\section{2 (3S)-3-Anilinocarbonyl-1,2,3,4- tetrahydroisoquinoline (8)}

To a stirred solution of (3S)-2-(tert-butoxycarbonyl)-3-anilinocarbonyl-1,2,3,4-tetrahydroisoquinoline (7) $(1.762 \mathrm{~g}, 5 \mathrm{mM})$ in $\mathrm{CH}_{2} \mathrm{Cl}_{2}$ was bubbled $\mathrm{HCl}$ gas for a period of $30 \mathrm{~min}$ at room temperature. Solvent was evaporated. The residue was dissolved in EtOAc $(50 \mathrm{~mL})$ and washed with saturated aqueous $\mathrm{NaHCO}_{3}$ solution $(50 \mathrm{~mL})$. The aqueous phase was then re-extracted with EtOAc $(25 \mathrm{~mL})$. The combined organic layer was dried over anhydrous $\mathrm{Na}_{2} \mathrm{SO}_{4}$ and the solvent was evaporated to provide the desired compound $\mathbf{8}$ as colourless solid. Yield: 93\% $\left.(1.175 \mathrm{~g}) .[\alpha]_{\mathrm{D}}^{25}:-81.16(c) 0.6, \mathrm{MeOH}\right)$, [TFA. Amide $^{24}[\alpha]_{\mathrm{D}}:^{25}-32.42(c 0.6, \mathrm{MeOH})$. It is worth mentioning here that $[\alpha]_{\mathrm{D}}^{25}$ of this salt changes to -58.63 on standing this solution $(12 \mathrm{~h})$ which might be attributed to the possible decomposition of this salt] $\left[\right.$ lit. ${ }^{25}$ 8-TFA salt $\left.[\alpha]_{\mathrm{D}}{ }^{20}:-33.1, c 1, \mathrm{MeOH}\right]$; m.p.: $160-162^{\circ} \mathrm{C}$ [lit. ${ }^{25} 150-152^{\circ} \mathrm{C}$ for 8-TFA salt]; IR (KBr): v 3300-2900 (multiple bands), 1678, $1601 \mathrm{~cm}^{-1} ;{ }^{1} \mathrm{H}$ NMR: $\delta 2.92(d d, 1 \mathrm{H}, J=10.8 \mathrm{~Hz}$. and $16.4 \mathrm{~Hz}), 3.35(d d, 1 \mathrm{H}, J=5.6 \mathrm{~Hz}$ and $16.4 \mathrm{~Hz})$, $3.69(d d, 1 \mathrm{H}, J=5.2 \mathrm{~Hz}$. and $10.8 \mathrm{~Hz}), 4.03$ and $4.08(\mathrm{ABq}, 2 \mathrm{H}, J=16.0 \mathrm{~Hz}), 7 \cdot 06-7 \cdot 38(m, 8 \mathrm{H})$, $7.61(d, 2 \mathrm{H}, J=8.0 \mathrm{~Hz}), 9.34(b r, 1 \mathrm{H}) ;{ }^{13} \mathrm{C}$ NMR: $\delta$ $30 \cdot 57,47 \cdot 55,56 \cdot 87,119 \cdot 48,124 \cdot 17,125 \cdot 57,126 \cdot 38$, $126 \cdot 82,129 \cdot 04,129 \cdot 22,134 \cdot 42,136 \cdot 11,137 \cdot 76$, $171 \cdot 31$

Crystal data for 8: Empirical formula, $\mathrm{C}_{16} \mathrm{H}_{16} \mathrm{~N}_{2} \mathrm{O}$; formula weight, 252.31; colourless, block crystal; crystal dimensions, $0.46 \times 0.37 \times 0.25 \mathrm{~mm}^{3}$; orthorhombic, lattice type, primitive; $a=5.8274(6) \AA$, $b=8.2330(8) \AA, c=27.680(3) \AA ; \alpha=90.00 ; \beta=$ $90.00 ; \gamma=90.00 ; \quad V=1328.0(2) \AA^{3}$; space group, P2(1)2(1)2(1) (International Table No. 19); $Z=4 ; D_{\text {calcd }}=1.262 \mathrm{~g} / \mathrm{cm}^{3} ; F_{\text {ooo }}=536 ; \lambda\left(\mathrm{MoK}_{\alpha}\right)=$ $0.71073 \AA ; \quad R \quad\left(I \geq 2 \sigma_{1}\right)=0.0399 ; \quad w R^{2}=0.0764$. Detailed X-ray crystallographic data is available from the Cambridge Crystallographic Data Centre, 12 Union Road, Cambridge CB2 1EZ, UK. ${ }^{26}$

\section{3 (3S)-3-Anilinomethyl-1,2,3,4- tetrahydroisoquinoline (1)}

This compound was prepared from compound $\mathbf{8}$ following the similar literature procedure ${ }^{7}$ with some modification. To a stirred suspension of lithium aluminium hydride $(0.228 \mathrm{~g}, 6 \mathrm{mM})$ in THF $(20 \mathrm{~mL})$, (3S)-3-anilinocarbonyl-1,2,3,4-tetrahydroisoquinoline $(0.504 \mathrm{~g}, 2 \mathrm{mM})$ was added portion-wise at room temperature. After the addition was complete, 
the reaction mixture was heated under reflux for $5 \mathrm{~h}$. The reaction mixture was cooled to $5^{\circ} \mathrm{C}$ and water $(1 \mathrm{~mL})$ was added carefully, followed by the addition of $\mathrm{NaOH}$ solution $(2.5 \mathrm{~N}, 5 \mathrm{~mL})$. The reaction mixture was diluted with dichloromethane $(10 \mathrm{~mL})$ and stirred for $10 \mathrm{~min}$. The organic layer was separated and the solid aluminium salts were washed with dichloromethane $(3 \times 10 \mathrm{~mL})$. The combined organic layer was dried over anhydrous $\mathrm{Na}_{2} \mathrm{SO}_{4}$. Solvent was evaporated and the residue thus obtained was purified by distillation [Bp: $180-182^{\circ} \mathrm{C}$ (oil bath) $/ 0.2 \mathrm{~mm}$ ] under reduced pressure to furnish the compound as a viscous liquid which solidified upon standing at room temperature. Yield: $84 \%$ $(0.40 \mathrm{~g}) ;[\alpha]_{\mathrm{D}}{ }^{25}:-64.79\left(c \quad 0.9, \mathrm{CHCl}_{3}\right)$; m.p.: 80$82^{\circ} \mathrm{C}$; IR (KBr): $v 3300,3213,1602 \mathrm{~cm}^{-1}$; ${ }^{1} \mathrm{H}$ NMR: $\delta 1.61-1.82(b r, 1 \mathrm{H}), 2.60-2.72(m, 1 \mathrm{H}), 2.80-2.90$ $(m, 1 \mathrm{H}), 3 \cdot 04-3 \cdot 14(m, 1 \mathrm{H}), 3 \cdot 15-3 \cdot 25(m, 1 \mathrm{H})$, $3.31-3.41(m, 1 \mathrm{H}), 4.06(s, 2 \mathrm{H}), 4.25(b r, 1 \mathrm{H}), 6.62-$ $6.76(m, 3 \mathrm{H}), 7 \cdot 01-7 \cdot 06(m, 1 \mathrm{H}), 7 \cdot 07-7 \cdot 22(m, 5 \mathrm{H})$; ${ }^{13} \mathrm{C}$ NMR: $\delta 33 \cdot 17,48 \cdot 16,49 \cdot 31,53 \cdot 10,113 \cdot 03$, $117 \cdot 57,125 \cdot 98,126 \cdot 10,126 \cdot 26,129 \cdot 33,129 \cdot 36$, 134.11, 135.80, 148.49; LCMS $(\mathrm{m} / \mathrm{z}): 239(\mathrm{M}+\mathrm{H})^{+}$; Anal. calcd. for $\mathrm{C}_{16} \mathrm{H}_{18} \mathrm{~N}_{2}: \mathrm{C}, 80.63 ; \mathrm{H}, 7.61 ; \mathrm{N}$, 11.75 ; Found: C, $80.83 ; \mathrm{H}, 7.67$; N, 11.68 .

\section{4 (R)-N-(tert-Butoxycarbonyl)-2-} anilinocarbonylpiperidine (14)

This compound was prepared ${ }^{7}$ from $(R)-\mathrm{N}-($ tertbutoxycarbonyl)pipecolinic acid (13) which was prepared from $(R)$-pipecolinic acid (12). Compound

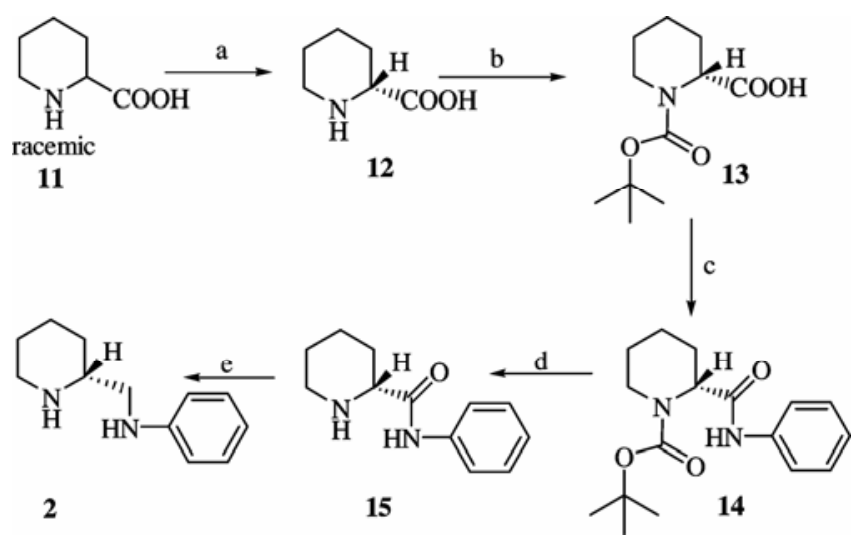

Scheme 2. (a) $(R, R)$-tartaric acid, $\mathrm{MeOH}, 60^{\circ} \mathrm{C}, 1 \mathrm{~h}$, $35 \% ;^{27}$ (b) $(\mathrm{Boc})_{2} \mathrm{O}$, aq. $\mathrm{NaOH}, \mathrm{THF}$, reflux, $6 \mathrm{~h}, 68 \%: 27$ (c) $\mathrm{NEt}_{3}, \mathrm{EtOCOCl}, \mathrm{PhNH}_{2}$, THF, r.t., $16 \mathrm{~h}, 75 \% ;^{7}$ (d) $\mathrm{CF}_{3} \mathrm{COOH}: \mathrm{CH}_{2} \mathrm{Cl}_{2}(1: 1)$, r.t., $1 \mathrm{~h}, 78 \%{ }^{7}$ (e) $\mathrm{LiAlH}_{4}$, THF, reflux, $5 \mathrm{~h}, 63 \%{ }^{7}$.
12 was obtained via resolution of racemic pipecolinic acid according to the literature procedure ${ }^{27}$ as presented in scheme 2 .

\section{5 (2R)-2-Anilinocarbonylpiperidine $(\mathbf{1 5})^{28}$}

This compound was prepared from the compound $\mathbf{1 4}$ following the similar procedure ${ }^{7}$ with some modification. To a stirred solution of $(R)-\mathrm{N}-($ tert-butoxycarbonyl)-2-anilinocarbonylpiperidine (1.52 g, $5 \mathrm{mM})$ in dichloromethane $(20 \mathrm{~mL})$ was added $20 \mathrm{~mL}$ of TFA at room temperature. After $1 \mathrm{~h}$ solvent was evaporated and the residue was dissolved in EtOAc $(50 \mathrm{~mL})$ and washed with saturated aqueous $\mathrm{NaHCO}_{3}$ solution $(50 \mathrm{~mL})$. The aqueous phase was then again extracted with EtOAc $(25 \mathrm{~mL})$. The combined organic layer was dried over anhydrous $\mathrm{Na}_{2} \mathrm{SO}_{4}$ and the solvent was evaporated. The residue thus obtained was purified by column chromatography (silica gel, $50 \%$ ethyl acetate in hexanes) to provide the desired compound as colourless solid. Yield: $78 \%(0.796 \mathrm{~g}) ;$ m.p.: $190-192^{\circ} \mathrm{C} ;[\alpha]_{\mathrm{D}}{ }^{25}$ : +18.82 ( c 1.0, MeOH); IR (KBr): v 3300-2849 (multiple bands), $1685,1601 \mathrm{~cm}^{-1} ;{ }^{1} \mathrm{H}$ NMR: $\delta$ $1.38-1.70(m, 4 \mathrm{H}), 1.74-1.91(m, 1 \mathrm{H}), 1.98-2.20$ $(m, 2 \mathrm{H}), 2.65-2.85(m, 1 \mathrm{H}), 2.97-3.16(m, 1 \mathrm{H})$, $3 \cdot 28-3.45(m, 1 \mathrm{H}), 7 \cdot 05-7 \cdot 16(m, 1 \mathrm{H}), 7 \cdot 25-7 \cdot 44$ $(m, 2 \mathrm{H}), 7.57(d, 2 \mathrm{H}, J=7.6 \mathrm{~Hz}), 8.88(b s, 1 \mathrm{H}) \cdot ;{ }^{13} \mathrm{C}$ NMR: $\delta 23 \cdot 84,25 \cdot 92,29 \cdot 67,45 \cdot 62,60 \cdot 51,119.53$, 124.07, 129.00, 137.90, 172.18.

Crystal data for amide 15-TFA salt: Empirical formula, $\mathrm{C}_{14} \mathrm{H}_{17} \mathrm{~F}_{3} \mathrm{~N}_{2} \mathrm{O}_{3}$; formula weight, 318.30; colourless, block; crystal dimensions, $0.45 \times 0.37 \times$ $0.25 \mathrm{~mm}^{3}$; monoclinic, lattice type, primitive; $a=23.409(3) \AA, b=8.0598(10) \AA, c=8.7079(10)$ $\AA ; \quad \alpha=90.00 ; \quad \beta=107.005 \quad(2) ; \quad \gamma=90.00 ; \quad V=$ 1571.1(3) $\AA^{3}$; space group, $C 2$ (International Table No. 5); $Z=4 ; \quad D_{\text {calcd }}=1.346 \mathrm{~g} / \mathrm{cm}^{3} ; \quad F_{\text {ooo }}=664$; $\lambda\left(\mathrm{MoK}_{\alpha}\right)=0.71073 \AA ; R\left(I \geq 2 \sigma_{1}\right)=0.0717 ; w R^{2}=$ $0 \cdot 2126$. Detailed $\mathrm{X}$-ray crystallographic data is available from the Cambridge Crystallographic Data Centre, 12 Union Road, Cambridge CB2 1EZ, UK. ${ }^{26}$

\section{6 (2R)-2-Anilinomethylpiperidine $(\mathbf{2})^{29}$}

This compound was prepared from the amide 15 according to the similar literature procedure ${ }^{7}$ described for the compound 1 as viscous liquid. Yield: $63 \%$; b.p.: $145-147^{\circ} \mathrm{C}$ (oil bath) $/ 0.5 \mathrm{~mm} ;[\alpha]_{\mathrm{D}}{ }^{25}:-29.02(\mathrm{c}$ $1.4, \mathrm{EtOH}$ ); IR (neat): $v 3381,3300,2928,1602 \mathrm{~cm}^{-1}$; ${ }^{1} \mathrm{H}$ NMR: $\delta 1 \cdot 14-1.28(m, 1 \mathrm{H}), 1.31-1.50(m, 2 \mathrm{H})$, 
$1.54-1.74(m, 2 \mathrm{H}), 1.78-2.05(m, 2 \mathrm{H}), 2.57-2.68$ (m, 1H), 2.72-2.83 (m, 1H), 2.94-3.20 ( $m, 3 \mathrm{H}), 4.03$ (br, 1H), 6.58-6.73 (m, 3H), 7.12-7.22 (m, 2H) $;{ }^{13} \mathrm{C}$ NMR: $\delta$ 24.51, 26.60, 30.75, 46.77, 50.09, 55.88, $112.73,117 \cdot 15,129 \cdot 18,148 \cdot 47$; LCMS $(\mathrm{m} / \mathrm{z}): 191$ $(\mathrm{M}+\mathrm{H})^{+}$; Anal. calcd. For $\mathrm{C}_{12} \mathrm{H}_{18} \mathrm{~N}_{2}: \mathrm{C}, 75.74 ; \mathrm{H}$, 9.53; N, 14.72; Found: C, 75.56; H, 9.50; N, 14.84.

\subsection{Asymmetric reduction of phenacyl bromide}

(9a) using the catalyst 1

2.7a Synthesis of (S)-2-bromo-1-phenylethanol [(S)-10a]: Representative procedure: To a stirred solution of (3S)-3-anilinomethyl-1,2,3,4-tetrahydroisoquinoline (1) $(0 \cdot 1 \mathrm{mM}, 1 \mathrm{~mL}, 0 \cdot 1 \mathrm{M}$ solution in toluene) in toluene $(2 \mathrm{~mL})$ was added $\mathrm{BH}_{3} . \mathrm{SMe}_{2}$ ( $1 \mathrm{mM}, 1 \mathrm{~mL}, 1 \mathrm{M}$ solution in toluene) at room temperature and the reaction mixture was heated under reflux for $15 \mathrm{~min}$. Then a solution of phenacyl bromide (9a) $(1 \mathrm{mM}, 0.199 \mathrm{~g})$, in toluene $(2 \mathrm{~mL})$, was added drop-wise and heated under reflux for further $30 \mathrm{~min}$. The reaction mixture was cooled to room temperature and quenched with $\mathrm{MeOH}$. Solvent was removed under reduced pressure and the residue thus obtained was purified by column chromatography (silica gel, $5 \%$ ethyl acetate in hexanes) to provide the desired $(S)$-2-bromo-1-phenylethanol [ $(S)$ $10 \mathrm{a}]$ in $86 \%(0.172 \mathrm{~g})$ yield as a colourless oil. $\left.[\alpha]_{\mathrm{D}}^{25}:+32.62(c) 0.9, \mathrm{CHCl}_{3}\right)\left[\right.$ lit. $^{30}[\alpha]_{\mathrm{D}}{ }^{25}:-39.0(c$ $\left.8.00, \mathrm{CHCl}_{3}\right),(R)$-configuration, $\left.93 \% \mathrm{ee}\right] ; 80 \%$ ee, the enantiomeric purity was determined by HPLC analysis using chiral column, [Chiralcel OD-H, $90: 10$ hexanes $/ i$-PrOH, $1.0 \mathrm{~mL} / \mathrm{min}, 254 \mathrm{~nm}$, retention times: $8.17 \mathrm{~min}(S)$ and $8.82 \mathrm{~min}(R)]$.

\section{$2.7 \mathrm{~b}$ (S)-2-Chloro-1-phenylethanol [(S)-10b]:} Colourless oil, $83 \%$ yield, $[\alpha]_{\mathrm{D}}{ }^{25}:+37.23$ (c 0.8 , cyclohexane) $\left[\right.$ lit. ${ }^{30}[\alpha]_{\mathrm{D}}{ }^{25}:-48 \cdot 10$ (c 1.73 , cyclohexane), $(R)$-configuration, $100 \% e e] ; 72 \% e e$, the enantiomeric purity was determined by HPLC analysis using chiral column [Chiralcel OD-H, 90:10 hexanes $/ i-\mathrm{PrOH}, 1.0 \mathrm{~mL} / \mathrm{min}, 254 \mathrm{~nm}$, retention times: $7.86 \mathrm{~min}(S)$ and $8.53 \mathrm{~min}(R)]$.

2.7c (S)-2-Bromo-1-(4-bromophenyl)ethanol [(S)10c]: Colourless solid, m.p.: $69-71^{\circ} \mathrm{C}\left[\mathrm{lit}^{19} \cdot 70\right.$ $\left.72^{\circ} \mathrm{C}\right] \quad 81 \%$ yield, $\left.[\alpha]_{\mathrm{D}}{ }^{25}:+27.51(c) 0.9, \mathrm{CHCl}_{3}\right)$ [lit. $\left.{ }^{31}[\alpha]_{\mathrm{D}}{ }^{25}:-31.0(c) 2.9, \mathrm{CHCl}_{3}\right),(R)$-configuration, $94 \% e e] ; 79 \%$ ee, the enantiomeric purity was determined by HPLC analysis using chiral column, [Chiralcel OJ-H, 95:5 hexanes $/ i-\mathrm{PrOH}$,
$1.0 \mathrm{~mL} / \mathrm{min}, 254 \mathrm{~nm}$, retention times: $19.87 \mathrm{~min}(R)$ and $21.03 \mathrm{~min}(S)]$.

2.7d (R)-1-Phenylethanol [(R)-10d]: Colourless oil, $84 \%$ yield, $[\alpha]_{\mathrm{D}}{ }^{25}:+23.54(c 0.8, \mathrm{MeOH})\left[\right.$ lit. $^{32}$ $[\alpha]_{\mathrm{D}}^{25}:+44 \cdot 1(c 3 \cdot 0, \mathrm{MeOH}),(R)$-configuration, $97 \%$ $e e] ; 57 \% e e$, the enantiomeric purity was determined by HPLC analysis using chiral column, [Chiralcel OD-H, $95: 5$ hexanes $/ i-\mathrm{PrOH}, 1.0 \mathrm{~mL} / \mathrm{min}, 254 \mathrm{~nm}$, retention times: $8.30 \mathrm{~min}(R)$ and $9.67 \mathrm{~min}(S)$ ].

\section{7e (R)-1-(4-Bromophenyl)ethanol $\quad[(R)-\mathbf{1 0 e}]$ :} Colourless oil, $83 \%$ yield, $[\alpha]_{\mathrm{D}}{ }^{25}:+21.5$ (c 0.5 , $\left.\mathrm{CHCl}_{3}\right)\left[\mathrm{lit}^{33}[\alpha]_{\mathrm{D}}{ }^{23}:-37.9\left(\mathrm{c} 1 \cdot 13, \mathrm{CHCl}_{3}\right),(S)\right.$ configuration, $>99 \% \mathrm{ee}$; $59 \% \mathrm{ee}$, the enantiomeric purity was determined by HPLC analysis using chiral column, [Chiralcel OJ-H, 95:5 hexanes $/ i-\mathrm{PrOH}$, $0.8 \mathrm{~mL} / \mathrm{min}, 254 \mathrm{~nm}$, retention times: $15.06 \mathrm{~min}(S)$ and $15.78 \mathrm{~min}(R)]$.

\section{Results and discussion}

Recently, we have demonstrated the application of chiral diamine i.e. (2S)-2-anilinomethylpyrrolidine (3) as a catalyst ${ }^{15}$ for the borane-mediated asymmetric reduction of prochiral ketones thus producing the resulting secondary alcohols in high enantiomeric purities. With a view to develop more effective catalysts based on the chiral diamine frameworks and also with an objective to understand the influence of the ring size and bicyclic ring system in the boranemediated asymmetric reduction of prochiral ketones we have selected two diamines i.e. (3S)-3-anilinomethyl-1,2,3,4-tetrahydroisoquinoline (1) and (2R)2-anilinomethylpiperidine (2) as in figure 1 (which were not examined earlier as catalysts for the borane-mediated asymmetric reduction of prochiral ketones) for our study.

Catalytic source 1 was prepared according to the reaction sequence as shown in scheme 1 starting from $(S)$-phenylalanine. Conversion of $(S)$-phenylalanine (4) into the corresponding (3S)-1,2,3,4-

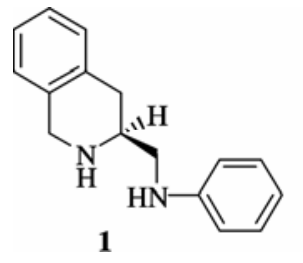

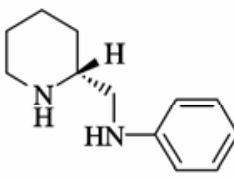

2

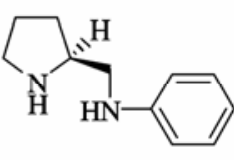

3
Figure 1. 
Table 1. Asymmetric reduction of phenacyl bromide (9a): Standardization ${ }^{\mathrm{a}}$.<smiles>O=C(CBr)c1ccccc1</smiles>

9a

(S)-10a

\begin{tabular}{lcccc}
\hline Entry & Catalyst $\mathbf{1}(\mathbf{m o l} \%)$ & Time $(\min )$ & $\begin{array}{c}\text { Yield }(\%) \\
[(\boldsymbol{S})-\mathbf{1 0 a})]\end{array}$ & $\begin{array}{c}\text { Enantiomeric purity }(\mathbf{\%}){ }^{\mathrm{c}}{ }^{\mathrm{b}} \\
[(\boldsymbol{S})-\mathbf{1 0 a})]\end{array}$ \\
\hline 1 & 5 & 45 & 78 & 68 \\
2 & $7 \cdot 5$ & 45 & 85 & 73 \\
3 & 10 & 45 & 84 & 78 \\
4 & 15 & 45 & 81 & 76 \\
5 & 20 & 45 & 82 & $\mathbf{8 0}$ \\
$\mathbf{6}$ & $\mathbf{1 0}$ & $\mathbf{3 0}$ & $\mathbf{8 6}$ & \\
\hline
\end{tabular}

${ }^{\mathrm{a}}$ All reactions were carried out on $1 \mathrm{mM}$ scale of phenacyl bromide with $\mathrm{BH}_{3} \cdot \mathrm{SMe}_{2}(1 \mathrm{mM})$ in the presence of 1 in toluene at $110^{\circ} \mathrm{C}$

${ }^{\mathrm{b}}$ Isolated yields of alcohols after purification by column chromatography (silica gel, 5\% ethyl acetate in hexanes)

${ }^{\mathrm{c}}$ Determined by HPLC analyses using the chiral column, Chiralcel OD-H

(a)

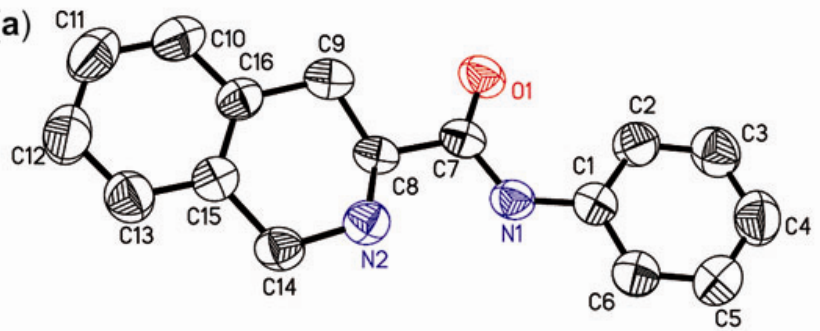

(b)

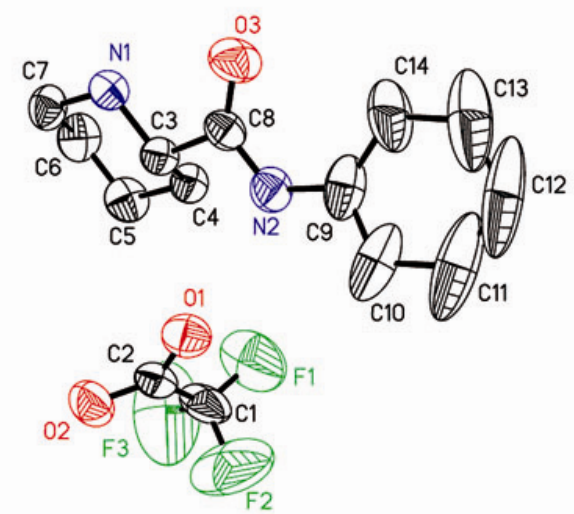

Figure 2. ORTEP diagram of (a) compound 8 and (b) compound 15-TFA salt (Hydrogen atoms were omitted for clarity).

tetrahydro-3-isoquinolinecarboxylic acid (5) is known in the literature. ${ }^{23}$ This acid (5) was conveniently transformed into (3S)-3-anilinomethyl-1,2,3,4tetrahydroisoquinoline (1) following the well known transformation methodologies. ${ }^{22,25}$ Our attempts to obtain single crystal for the diamine (1) were not successful. Since the single crystal X-ray structure of (3S)-3-anilinocarbonyl-1,2,3,4-tetrahydroisoquinoline (8) was not reported in the literature (although this amide is known in the literature), ${ }^{25}$ we thought it would also be appropriate to report the single crystal $\mathrm{X}$-ray data for this amide (8). We obtained single crystal for the amide (8) and confirmed the structure by the single crystal X-ray data (ORTEP diagram: figure 2$)^{26}$ thus indirectly further confirming the structure of the diamine (1).

We have first selected phenacyl bromide (9a) as a substrate for our study and performed the boranemediated asymmetric reduction of $\mathbf{9 a}$ using varying catalytic amounts of the compound 1 . The best result was obtained when phenacyl bromide (9a) $(1 \mathrm{mM})$ was treated with borane $\left(\mathrm{BH}_{3}: \mathrm{SMe}_{2}, 1 \mathrm{mM}\right)$ in the presence of $10 \mathrm{~mol} \%$ catalyst at reflux temperature for $30 \mathrm{~min}$ thus providing the resulting secondary alcohol, (S)-2-bromo-1-phenylethanol $(S)-10 a$ in $80 \%$ enantiomeric purity (table $1,(1))$. Encouraged by this result, we have subjected representative class of prochiral ketones $(\mathbf{9 b}-\mathbf{e})$ to this strategy to afford the corresponding secondary alcohols $(S)-\mathbf{1 0 b}, \mathrm{c}$ and $(R)-10 \mathrm{~d}, \mathrm{e}$ in $57-80 \%$ enantiomeric purities (table 2).

Although the results are not as encouraging as in the case of diamine (3) ${ }^{15}$ these results certainly throw 
Table 2. Asymmetric reduction of representative ketones by catalytic source $\mathbf{1}^{\mathrm{a}}$.

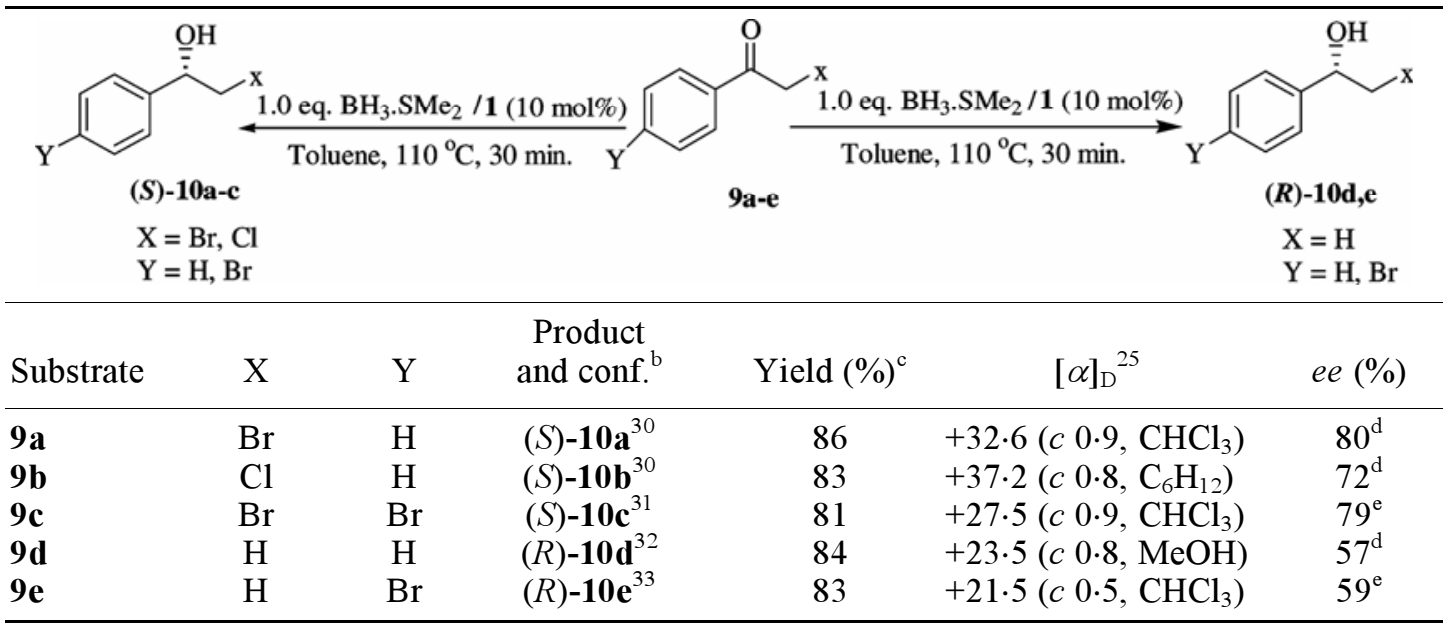

${ }^{a}$ All reactions were carried out on $1 \mathrm{mM}$ scale of ketone with $\mathrm{BH}_{3} \cdot \mathrm{SMe}_{2}(1 \mathrm{mM})$ in the presence of the catalyst $1(10 \mathrm{~mol} \%)$ in toluene for $30 \mathrm{~min}$ at $110^{\circ} \mathrm{C}$

${ }^{\mathrm{b}}$ Absolute configuration was assigned by comparison of the sign of specific rotation with that of the reported molecules

${ }^{c}$ Isolated yields of alcohols after purification by column chromatography (silica gel, 5\% ethyl acetate in hexanes)

${ }^{\mathrm{d}}$ Determined by HPLC analyses using the chiral column, Chiralcel OD-H

${ }^{\mathrm{e}}$ Determined by HPLC analyses using the chiral column, Chiralcel OJ-H

Table 3. Asymmetric reduction of representative ketones by catalytic source $\mathbf{2}^{\mathrm{a}}$.

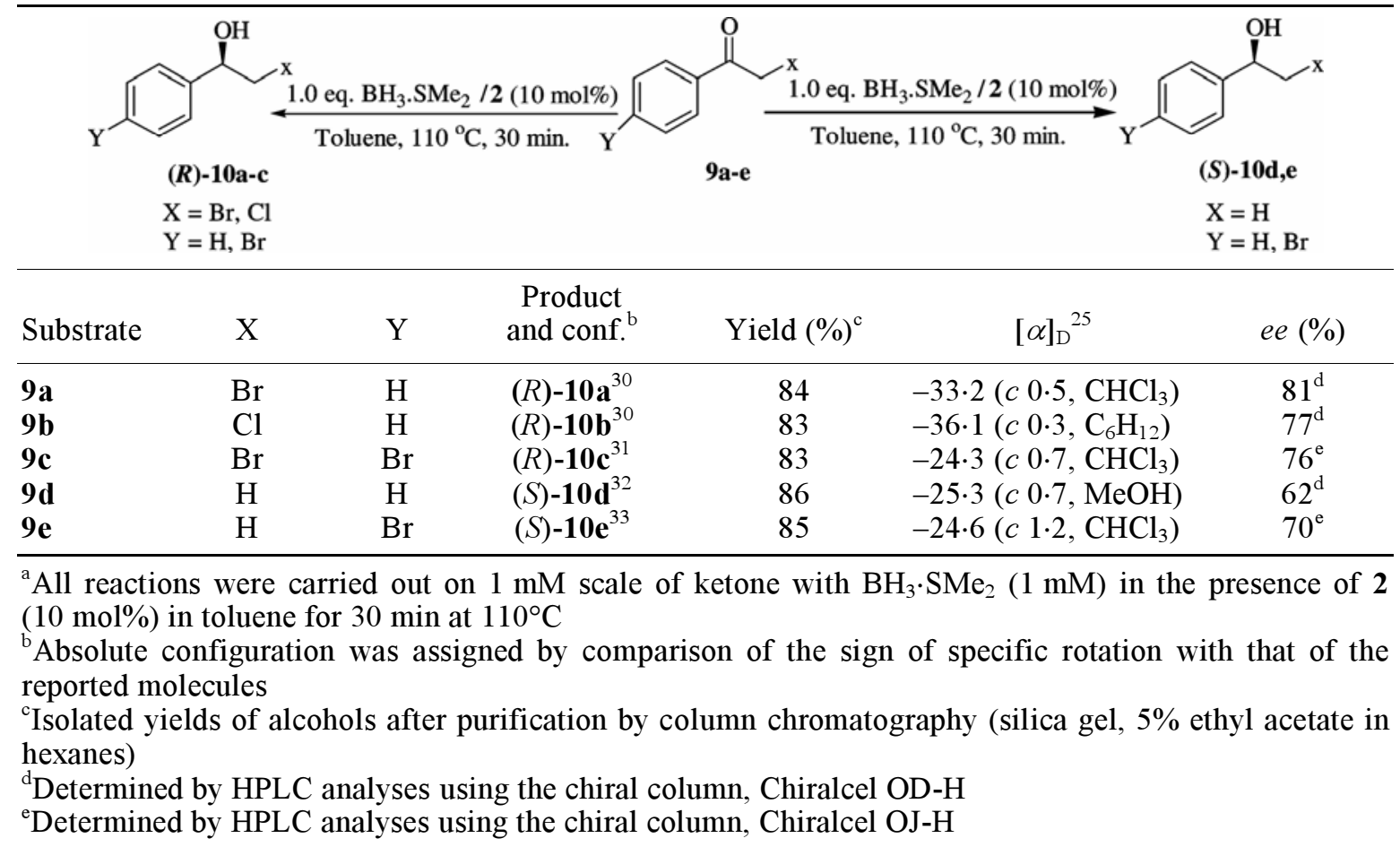

some light in understanding the structural aspects of the catalyst to provide more enantioselectivities. We have next turned our attention towards the application of (2R)-2-anilinomethylpiperidine $(2)^{29}$ as a catalyst in the borane-mediated reduction processes. This diamine (2) was prepared following the reaction sequence as described in scheme 2 starting from the $(R)$-pipecolinic acid (12) which was obtained via 
the resolution of racemic pipecolinic acid using $(R, R)-(+)$-tartaric acid according to the known procedure $^{27}$. We could obtain single crystal for the amide $(\mathbf{1 5})^{28}$ and confirmed the structure of amide [indirectly confirming the structure of the diamine (2)] by single crystal X-ray data of the corresponding amide (15) as its triflouroacetate (TFA) salt (figure 2$)^{26}$ as this diamine is a liquid (low melting solid)]. We have then examined the potential of this diamine (2) as a possible chiral catalyst for the borane-mediated reduction of representative prochiral ketones $(9 \mathbf{a}-\mathbf{e})$ using $10 \mathrm{~mol} \% \mathbf{2}$, to provide the resulting secondary alcohols $[(R)-\mathbf{1 0 a}-\mathbf{c}$ and $(S)-\mathbf{1 0 d}$, e] in $62-81 \%$ enantiomeric purities (table 3 ). As expected the diamine 2 with $R$-configuration provided the resulting secondary alcohols with opposite configuration as that of the chiral diamine (1) and (3) with $S$-configuration.

\section{Conclusion}

From these it is clear that the chiral diamines (3S)-3anilinomethyl-1,2,3,4-tetrahydroisoquinoline (1) and (2R)-2-anilinomethylpiperidine (2) are inferior to (2S)-2-anilinomethylpyrrolidine (3) in these reduction procedures. Although we can not generalize, on the basis of these two catalysts, that all six membered ring catalysts provide inferior selectivities than the corresponding five membered ring catalysts these studies certainly throw some light on the understanding of the structural framework of diamine catalysts which actually play a key role to provide high enantioselectivities. Our studies are in progress in understanding these structural aspects of the diamine-based catalysts with a view to have high enantioselectivities.

\section{Acknowledgements}

We thank Council for Scientific and Industrial Research (CSIR), New Delhi for funding this project. We also thank University Grants Commission (UGC), New Delhi for recognizing our University of Hyderabad as University with Potential for Excellence (UPE) and also recognizing the School of Chemistry as a "Center for Advanced Studies in Chemistry' and providing some instrumental facilities. UD and SR thank CSIR, New Delhi for their research Fellowships. We also thank the National Single Crystal X-ray Facility in our School of Chemistry funded by the Department of Science and
Technology (DST), New Delhi. We thank Professor S Pal for helpful discussions regarding the X-ray crystal structure.

\section{References}

1. HobuB D, Baro A, Laschat S and Frey W 2008 Tetrahedron 641635

2. Olivares-Romero J L and Juaristi E 2008 Tetrahedron 649992

3. Du D-M, Fang T, Xu J and Zang S-W 2006 Org. Lett. 81327

4. Fang T, Xu J and Du D.-M 2006 Synlett 1559

5. Cho B T 2006 Tetrahedron $\mathbf{6 2} 7621$

6. Asami M, Sato S and Watanabe H 2000 Chem. Lett. 990

7. Sato S, Watanabe H and Asami M 2000 Tetrahedron: Asymmetry 114329

8. Singh V K 1992 Synthesis 605

9. Deloux L and Srebnik M 1993 Chem. Rev. 93 763

10. Corey E J and Helal C J 1998 Angew. Chem. Int. Ed. 371986

11. Gamble M P, Smith A R C and Wills M 1998 J. Org. Chem. 636068

12. Gamble M P, Studley J R and Wills M 1996 Tetrahedron: Asymmetry 73071

13. Basavaiah D, Venkateswara Rao K and Sekhara Reddy B 2007 Tetrahedron: Asymmetry 18968

14. Basavaiah D, Venkateswara Rao K and Sekhara Reddy B 2007 Tetrahedron: Asymmetry 18963

15. Basavaiah D, Venkateswara Rao K and Sekhara Reddy B 2006 Tetrahedron: Asymmetry 171041

16. Basavaiah D, Venkateswara Rao K and Sekhara Reddy B 2006 Tetrahedron: Asymmetry 171036

17. Basavaiah D, Chandrashekar V, Das U and Jayapal Reddy G 2005 Tetrahedron: Asymmetry 163955

18. Basavaiah D, Jayapal Reddy $G$ and Venkateswara Rao K 2004 Tetrahedron: Asymmetry 151881

19. Basavaiah D, Jayapal Reddy G and Chandrashekar V 2004 Tetrahedron: Asymmetry 1547

20. Basavaiah D, Jayapal Reddy G and Chandrashekar V 2002 Tetrahedron: Asymmetry 131125

21. Basavaiah D, Jayapal Reddy $G$ and Chandrashekar V 2001 Tetrahedron: Asymmetry 12685

22. Charton, J, Gassiot A C, Melnyk P, Girault-Mizzi S and Sergheraert C 2004 Tetrahedron Lett. 457081

23. Tarver Jr. J E, Pfizenmayer A J and Joullie M M $2001 \mathrm{~J}$. Org. Chem. 667575

24. TFA-amide was prepared via the treatment of amide $8(0.1 \mathrm{mM}, 25 \mathrm{mg})$ in dichlomethane $(1 \mathrm{~mL})$ with trifluoroacetic acid $(1 \mathrm{~mL})$ at $0^{\circ} \mathrm{C}$ and then stirring at room temperature for $30 \mathrm{~min}$, followed by evaporation of all the solvents under reduced pressure

25. Balboni G, Salvadori S, Guerrini R, Negri L, Giannini E, Bryant S D, Jinsmaa Y and Lazarus L H 2003 Bioorg. Med. Chem. 115435

26. CCDC \# 712121 for compound 8 and CCDC \# 712122 for compound 15.TFA 
27. Shannon C, Paul D, Donald Jr. R G, John L and Ronald Jr. H S 2005 Chem. Abstr. 143 266823k

28. This compound is known in literature. Ref: Nemak K, Acs M, Jaszay Z M, Kozma D and Fogassy E 1996 Tetrahedron $\mathbf{5 2} 1637$

29. Racemic compound is known in the literature. Ref: Crabb T A and Newton R F 1969 J. Heterocyclic Chem. 6301
30. Imuta M, Kawai K-i and Ziffer H $1980 \mathrm{~J}$. Org. Chem. 453352

31. Hiratake J, Inagaki M, Nishioka T and Oda J $1988 \mathrm{~J}$. Org. Chem. 536130

32. Prasad K R K and Joshi N N 1996 Tetrahedron: Asymmetry 73147

33. Nakamura K and Matsuda T 1998 J. Org. Chem. 63 8957 